\title{
Assessment of the validity of image- defined risk factors (IDRFs) in abdominal neuroblastoma
}

\author{
Ahmed Hassan Ali Mohamed ${ }^{1 *}$ (D), Ikram Hamed Mahmoud ${ }^{1}$, Hadeel Mohammed Seif El Dein², \\ Kareem Raouf Sallam ${ }^{3}$ and Hisham Samir Wahba ${ }^{1}$
}

\begin{abstract}
Background: Neuroblastoma is the third most common childhood cancer. It is the most common extra-cranial solid tumor of childhood. It accounts for about 15\% of all pediatric cancer fatalities.

The International Neuroblastoma Risk Group (INRG) Project proposed a new staging system which is dependent on whether image-defined risk factors (IDRFs) are or are not present, and IDRFs are surgical risk factors, detected on images, that make total tumor excision risky or difficult.

The purpose of the study is to assess the validity of using the image-defined risk factors (IDRFs) of abdominal neuroblastoma as predictors of the surgical resectability and complications.

Methods: We retrospectively studied the clinical, imaging, and surgical data of 43 patients with abdominal neuroblastoma, and then the results were correlated with each. For comparing categorical data, chi-square $\left(X^{2}\right)$ test was performed. $P$ values less than 0.05 were considered as statistically significant.

Results: At least 1 pre-operative IDRF was present in 33 cases (76.7\%), and they were absent in 10 cases (23.3\%). There was statistical significant correlation between the pre-operative IDRFs and surgical resectability, and the complete resection rate if no IDRF was found was $80 \%$ in this study. Out of the 13 cases with surgical complications, pre-operative IDRFs were present in 12 cases.

Conclusion: The neuroblastoma IDRFs are useful predictors of the surgical resectability and the risk of surgical complications and should be considered in surgical planning.
\end{abstract}

Keywords: Neuroblastoma, IDRF (image-defined risk factor), CT (computed tomography)

PACS picture archiving and communicating system IV Intravenous

mA Milliampere

KV Kilovoltage

DWI Diffusion-weighted images

LR Low risk

HR High risk

IR Intermediate risk

* Correspondence: doc.ahmedhassan@gmail.com;

ahmed.hassan@nci.cu.edu.eg

${ }^{1}$ National Cancer Institute, Cairo university, Kasr El- Aini St., Fom El Khalig,

Cairo, Egypt

Full list of author information is available at the end of the article
SPSS Statistical package for the social sciences

IVC Inferior vena cava

SMA Superior mesenteric artery

SIOPEN The European International Society of Pediatric Oncology Neuroblastoma Group

GPOH The German Society for Pediatric Haematology and Oncology

\section{Background}

Neuroblastoma is a complex heterogeneous disease that arises from the embryonic cells that form the primitive neural crest [1]. Neuroblastoma is the third most common childhood cancer. It is the most common extra-cranial
Springer Open

(c) The Author(s). 2020 Open Access This article is licensed under a Creative Commons Attribution 4.0 International License, which permits use, sharing, adaptation, distribution and reproduction in any medium or format, as long as you give appropriate credit to the original author(s) and the source, provide a link to the Creative Commons licence, and indicate if changes were made. The images or other third party material in this article are included in the article's Creative Commons licence, unless indicated otherwise in a credit line to the material. If material is not included in the article's Creative Commons licence and your intended use is not permitted by statutory regulation or exceeds the permitted use, you will need to obtain permission directly from the copyright holder. To view a copy of this licence, visit http://creativecommons.org/licenses/by/4.0/. 
solid tumor of childhood. It accounts for about $15 \%$ of all pediatric cancer fatalities. It can occur anywhere within the sympathetic nervous system, and about $46 \%$ of neuroblastoma arise from the adrenal gland [2].

Histologically, neuroblastoma falls into a category of malignant small round cell tumors. These tumors demonstrate small, round, relatively undifferentiated cells [1].

The clinical features of neuroblastoma are highly variable and ultimately depend on the site of the primary lesion, the extent of metastatic disease, and the presence of associated paraneoplastic syndromes [3].

Neuroblastoma has a variable prognosis; tumor stage, patient age, tumor oncogenes, and DNA content are all known to be implicated [4].

Genetic analysis of the tumor is an important component of risk stratification and determining the prognostic effect of neuroblastoma. Molecular classification of tumors is now a routine due to the influence of genetic variations on outcome [1] MYCN gene amplification and ploidy have been linked to neuroblastoma prognosis for more than 2 decades, and many more genetic abnormalities have been identified [1].

Imaging plays a central role in the diagnosis, staging, response evaluation, and follow-up. Once a provisional diagnosis of NB is made, a cross-sectional imaging study, computed tomography $(\mathrm{CT})$, or magnetic resonance imaging (MRI) needs to be performed [5].

There is currently no consensus about the optimal imaging modality for assessing local disease. Both MR imaging and $\mathrm{CT}$ are routinely used, depending on local availability and the radiologist's preference. In one multi-institutional study, CT and MR imaging had statistically similar performance in assessing the features of local disease. There is no clear evidence as to which modality is superior, as each comes with its own inherent pros and cons [5]. Imaging cannot reliably differentiate NB from other neuroblastic tumors like ganglioneuroma or ganglioneuroblastoma that occur in the same locations, though ganglioneuroma tends to be more homogeneous. Histopathological confirmation is mandatory in a case of suspected NB [5].

Several staging systems have been developed to classify the extent of disease in neuroblastoma patients at the time of diagnosis [7].

\section{The international neuroblastoma staging system (INSS)}

The International Neuroblastoma Staging System (INSS) (Table 1), developed in 1988 and modified in 1993, is still used by most cooperative groups [6].

However, the INSS is not suitable for the pretreatment risk classification of localized disease, as this staging is based on the tumor resection extent. The same tumor can be classified as INSS stage 1 or 3 disease depending on the extent of surgical excision, making direct comparisons of clinical trials based on the INSS difficult. Another limitation is that assessment of lymph node involvement is necessary for proper staging. However, lymph node sampling is subject to the thoroughness of the individual surgeon, and the assessment of extra- regional lymph node involvement is difficult to apply uniformly [8].

\section{The international neuroblastoma risk group staging system (INRGSS)}

In 2004, investigators from the major cooperative groups formed the International Neuroblastoma Risk Group (INRG) Task Force, which developed the INRG Staging System (INRGSS) and the INRG Risk Classification System for neuroblastoma. The INRGSS, published in 2009, is designed for tumor staging before surgery or any other treatment (Table 2) [6].

Localized tumors are classified as stage L1 or L2 disease on the basis of whether one or more of 20 imagedefined risk factors (IDRFs) are present (Table 3). Stage $\mathrm{M}$ indicates disseminated disease (comparable to the INSS stage 4), and stage MS indicates metastatic disease similar to INSS stage $4 \mathrm{~S}$ disease (with exception of primary tumor size and patient age range) [6].

IDRFs are surgical risk factors, identified on images, that make complete tumor resection risky or difficult at the time of diagnosis. It is based upon the previously defined surgical risk factors SRFs, which are predictors of adverse surgical outcome because their presence was associated with lower complete resection rate and greater risk of surgery related complications [6].

Compared with the focus on surgicopathologic findings in the INSS, the focus has now shifted to imaging in the INRGSS [6]. The IDRFs may also be used at reassessments during treatment and should also be assessed in metastatic disease-although it is staged regardless of the loco-regional extent-to-aid surgical [6].

The INRGSS differs from INSS in four important ways: first, it is based on pre-operative imaging and IDRFs, not surgicopathologic findings. Second, the midline is not included in the staging criteria of the INRGSS. Third, lymph node status is not included in the staging of localized disease [1]. Lymph nodes are now classified as regional or non-regional rather than ipsilateral, contralateral, or distant. Fourth, whereas INSS stage $4 \mathrm{~S}$ has an upper age limit of 12 months, the Task Force decided to extend the age group for stage MS to patients younger than 18 months [8].

The aim of this study was to assess the validity of using the image-defined risk factors (IDRFs) of abdominal neuroblastoma as predictors of the surgical resectability and complications, to answer the question whether they can be used as a reliable factors in staging or not. 
Table 1 Descriptions of original INSS tumor stages [6]

\begin{tabular}{|c|c|}
\hline $\begin{array}{l}\text { Tumor } \\
\text { stage }\end{array}$ & Description \\
\hline 1 & $\begin{array}{l}\text { Localized tumor with complete gross excision, with or without microscopic residual disease; representative ipsilateral lymph nodes } \\
\text { negative for tumor microscopically. Nodes attached to and removed with the primary tumor may be positive. }\end{array}$ \\
\hline $2 \mathrm{~A}$ & $\begin{array}{l}\text { Localized tumor with incomplete gross excision; representative ipsilateral non-adherent lymph nodes negative for tumor } \\
\text { microscopically. }\end{array}$ \\
\hline $2 B$ & $\begin{array}{l}\text { Localized tumor with or without complete gross excision, with ipsilateral non-adherent lymph nodes positive for tumor; enlarged } \\
\text { contralateral lymph nodes negative microscopically. }\end{array}$ \\
\hline 3 & $\begin{array}{l}\text { Unresectable unilateral tumor infiltrating across the midline (beyond the opposite side of the vertebral column) with or without regional } \\
\text { lymph node involvement or midline tumor with bilateral extension via infiltration (unresectable) or lymph node involvement. }\end{array}$ \\
\hline 4 & $\begin{array}{l}\text { Any primary tumor with dissemination to distant lymph nodes, bone, bone marrow, liver, skin, and/or other organs (except as defined } \\
\text { for stage } 4 \mathrm{~S} \text { disease). }\end{array}$ \\
\hline $4 S$ & $\begin{array}{l}\text { Localized primary tumor (as defined for stage 1, } 2 \mathrm{~A} \text {, or } 2 \mathrm{~B} \text { disease) with dissemination limited to skin, liver, and/or bone marrow (limited } \\
\text { to infants younger than } 1 \text { year, marrow involvement of less } 10 \% \text { of total nucleated cells, and MIBG scan findings negative in the } \\
\text { marrow). }\end{array}$ \\
\hline
\end{tabular}

The clinical, imaging, and surgical data of abdominal neuroblastoma patients were collected, analyzed, and correlated with each other, and the results were then compared to those of previous studies.

\section{Methods}

This retrospective study involved patients with abdominal neuroblastic tumor who were managed between January 2014 and September 2019.

Inclusion criteria were as follows: patients with pathologically proven abdominal neuroblastic tumor, and patients underwent surgical intervention, with available pre-operative imaging data and full operative data. Cases were excluded if patients had the primary tumor outside the abdomen; patients were not candidates for surgery or surgery that was refused, and patients with incomplete pre-operative imaging data or no operative data.

Clinical data involving age, initial presentation, stage (according to INSS and INRGSS), and the risk classification (according to INRGSS and children's oncology group (COG)) were recorded. Regarding the INRGSS risk, as in some cases, it depends on 11q aberration or ploidy which was unavailable; in these cases, we assigned the risk to the higher stage.

Prognostic factors including MYCN gene amplification and histology classification (favourable or unfavourable), and the grade of tumor differentiation were recorded if available.

Imaging data (CT and/or MRI) were extracted from the Picture Archiving and Communicating System (PACS).
Imaging data were obtained for the pre-operative images (essential in all cases, if not available, the case was excluded) as well as initial and post-operative images (if available). The interpretation of the images was done by an experienced radiologist, and he was not aware of the extent of tumor resection or surgery associated complications when reviewing the images and reports.

The pre-operative images (performed within a range of 2 weeks before surgery) were interpreted for the presence of any IDRF. The initial images (at time of diagnosis/before any treatment) (if available) were also interpreted for the presence of initial IDRFs. For the cases who received chemotherapy, the changes of the IDRFs after chemotherapy between the initial and preoperative images were recorded (whether decreased, totally disappeared, or remain stable). Post-operative images (if available) (performed within a range of 1 month after surgery) were interpreted for the assessment of the extent of surgical resection.

\section{CT examination protocol design}

CT exams were performed on a GE light speed VCT 64 multislice $\mathrm{CT}$ scanner and GE optima 16 slice CT scanner.

CT chest, abdomen and pelvis, with IV contrast was performed using the following parameters: $(350 \mathrm{~mA}, 100$ $\mathrm{KV}, 0.5 \mathrm{~s}$ tube rotation time, slice thickness $5 \mathrm{~mm}, 8 \mathrm{~mm}$ table feed, and $3 \mathrm{~mm}$ incremental reconstruction).

Table 2 Descriptions of INRG tumor stages [6]

\begin{tabular}{ll}
\hline Tumor stage & Description \\
\hline L1 & Localized tumor not involving vital structures, as defined by the list of IDRFs, and confined to one body compartment \\
L2 & Local-regional tumor with presence of one or more IDRFs \\
MS & Distant metastatic disease (except stage MS tumor) \\
\hline
\end{tabular}


Table 3 Image-defined risk factors in Neuroblastoma [8]

\begin{tabular}{|c|c|}
\hline Anatomic region & Description \\
\hline Multiple body compartments & $\begin{array}{l}\text { Ipsilateral tumor extension within two body compartments (i.e., neck and chest, chest and abdomen, or } \\
\text { abdomen and pelvis). }\end{array}$ \\
\hline Neck & $\begin{array}{l}\text { Tumor encasing carotid artery, vertebral artery, and/or internal jugular vein. } \\
\text { Tumor extending to skull base. } \\
\text { Tumor compressing the trachea. }\end{array}$ \\
\hline Cervicothoracic junction & $\begin{array}{l}\text { Tumor encasing brachial plexus roots. } \\
\text { Tumor encasing subclavian vessels, vertebral artery, and/or carotid artery. } \\
\text { Tumor compressing the trachea. }\end{array}$ \\
\hline Thorax & $\begin{array}{l}\text { Tumor encasing aorta and/or major branches. } \\
\text { Tumor compressing trachea and/or principal bronchi. } \\
\text { Lower mediastinal tumor infiltrating costo-vertebral junction between T9 and T12 vertebral levels. }\end{array}$ \\
\hline Thoracoabdominal Junction & Tumor encasing aorta and/or vena cava. \\
\hline Abdomen and pelvis & $\begin{array}{l}\text { Tumor infiltrating porta hepatis and/or hepatoduodenal ligament. } \\
\text { Tumor encasing branches of superior mesenteric artery (SMA) at the mesenteric root. } \\
\text { Tumor encasing origin of celiac axis and/or origin of the superior mesenteric artery. } \\
\text { Tumor invading one or both renal pedicles. } \\
\text { Tumor encasing aorta and/or vena cava. } \\
\text { Tumor encasing iliac vessels. } \\
\text { Pelvic tumor crossing sciatic notch. }\end{array}$ \\
\hline Intraspinal tumor extension & $\begin{array}{l}\text { Intraspinal tumor extension whatever the location provided that more than one third of spinal canal in the } \\
\text { axial plane is invaded, the perimedullary leptomeningeal spaces are not visible, or the spinal cord signal } \\
\text { intensity is abnormal. }\end{array}$ \\
\hline $\begin{array}{l}\text { Infiltration of adjacent organs and } \\
\text { structures }\end{array}$ & Pericardium, diaphragm, kidney, liver, duodenopancreatic block, and mesentery. \\
\hline $\begin{array}{l}\text { Conditions to be recorded, but not } \\
\text { considered IDRF. }\end{array}$ & $\begin{array}{l}\text { Multifocal primary tumors, pleural effusion with or without malignant cells, ascites with or without malignant } \\
\text { cells. }\end{array}$ \\
\hline
\end{tabular}

\section{MRI examination protocol design}

MRI examinations were performed on a $1.5 \mathrm{~T}$ scanner (Achieva, Philips Medical Systems, Best, Netherlands, Release 2.6, Level 3).

The used sequences were:

- Axial T1, T2, and coronal T2 weighted images

- Post-contrast axial T1, +/- coronal T1, +/- sagittal T1.

- DWI (at $b$ values $=0$ and $1000 \mathrm{~s} / \mathrm{mm}^{2}$ in axial orientation).

Regarding the surgical data, primary operation was defined as resection (other than a biopsy) before any adjuvant chemotherapy, while a secondary operation was defined as a resection (other than a biopsy) after neoadjuvant chemotherapy.

According to the treatment protocols, surgery was primary for low-risk (LR) patients and secondary after chemotherapy for intermediate risk (IR) and high risk (HR) patients, after the 4th and 5th cycles respectively, aiming at maximum safe resection, unless otherwise indicated by multidisciplinary decision.

The surgical resectability was assessed from operative reports, pathological reports, and post-operative imaging (CT or MRI). it was defined as the macroscopic removal of the tumor and categorized into complete resection
(100\%), near complete resection (90-99\%), incomplete resection (50-89\%), and biopsy/ resection $<50 \%$.

Surgical complications were defined as intraoperative or post-operative major complications due to surgery, and commonly accepted definitions of surgical complications do not exist. Surgery-related death was defined as death occurring within 60 days from the initial operation. The different data used in the research methodology are demonstrated in Fig. 1.

\section{Statistical analysis}

Data were coded and entered using the statistical package for the Social Sciences (SPSS) version 25 (IBM Corp., Armonk, NY, USA). Data was summarized using mean, standard deviation, median, minimum and maximum in quantitative data, and using frequency (count) and relative frequency (percentage) for categorical data. For comparing categorical data, chi-square $\left(\chi^{2}\right)$ test was performed. Exact test was used instead when the expected frequency is less than 5 [9]. $P$ values less than 0.05 were considered as statistically significant.

\section{Results}

This retrospective study involved 43 patients (28 males and 15 females) with abdominal neuroblastic tumor.

Their mean age in months was 48.6 months, according to age groups: 2 cases were less than 12 months, 5 cases 


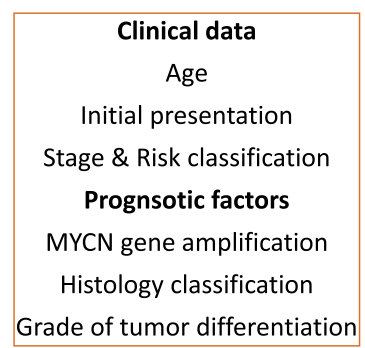

Grade of tumor differentiation
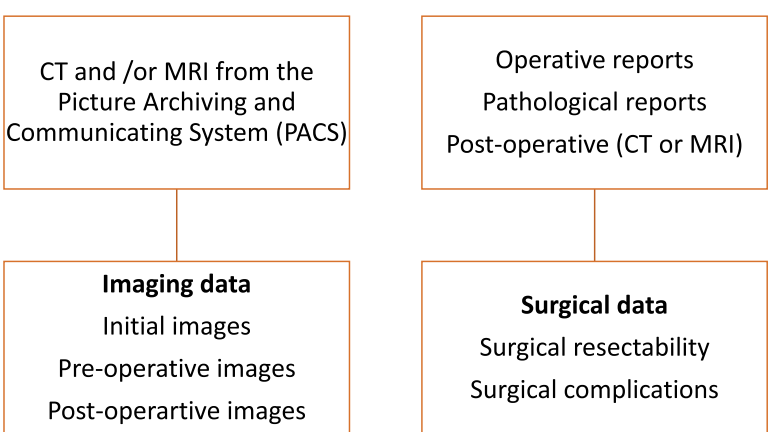

Fig. 1 The different data used in the research methodology

ranged from 12 to less than 18 months, and 36 cases were more than 18 months.

The histological categories were 40 cases of neuroblastoma, 2 cases ganglioneuroblastoma, nodular, and 1 case ganglioneuroblastoma, intermixed. The histological classification was mentioned in 37 cases out of the 43 cases of the study, from which 6 cases $(16.2 \%)$ were favorable, and 31 cases $(83.8 \%)$ were unfavorable.

MYCN gene was amplified in 10 cases (23.3\%), not amplified in 23 cases (53.5\%), and unknown/not analyzed in 10 cases $(23.3 \%)$.

Metastasis was present in 33 cases $(76.7 \%)$ and absent in 10 cases $(23.3 \%)$, with the bone is the most common site (32 cases) followed by lymph nodes (6 cases), liver ( 2 cases), and skin (1 case).
According to the INRGSS, 1 case was stage L1, 8 cases were stage $\mathrm{L} 2$, and 34 case were stage $\mathrm{M}$.

According to the INRGSS risk classification, 2 cases were very low risk, 7 cases were intermediate risk (IR), and 34 cases were high risk (HR).

As for the imaging data, a total of 122 examinations were obtained (43 pre-operative, 39 initial, and 40 postoperative examinations). All the imaging studies were CT examinations, except for 3 MRI examinations (two initial and one post-operative examination).

Regarding the pre-operative image-defined risk factors, from the 43 cases of the study, at least 1 IDRF was present in 33 cases $(76.7 \%)$, and they were absent in 10 cases $(23.3 \%)$. The most frequent pre-operative IDRF was invasion of one or both renal pedicles, and it was

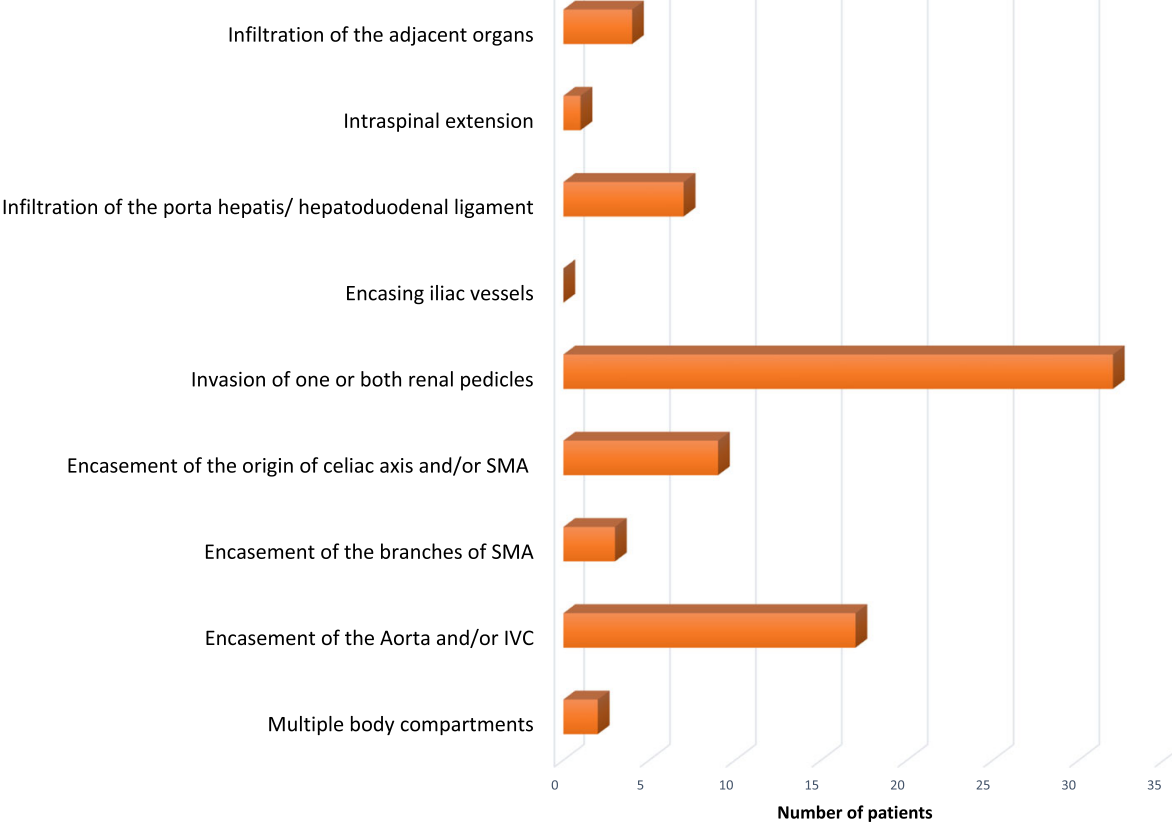

Fig. 2 The number of each pre-operative IDRF 


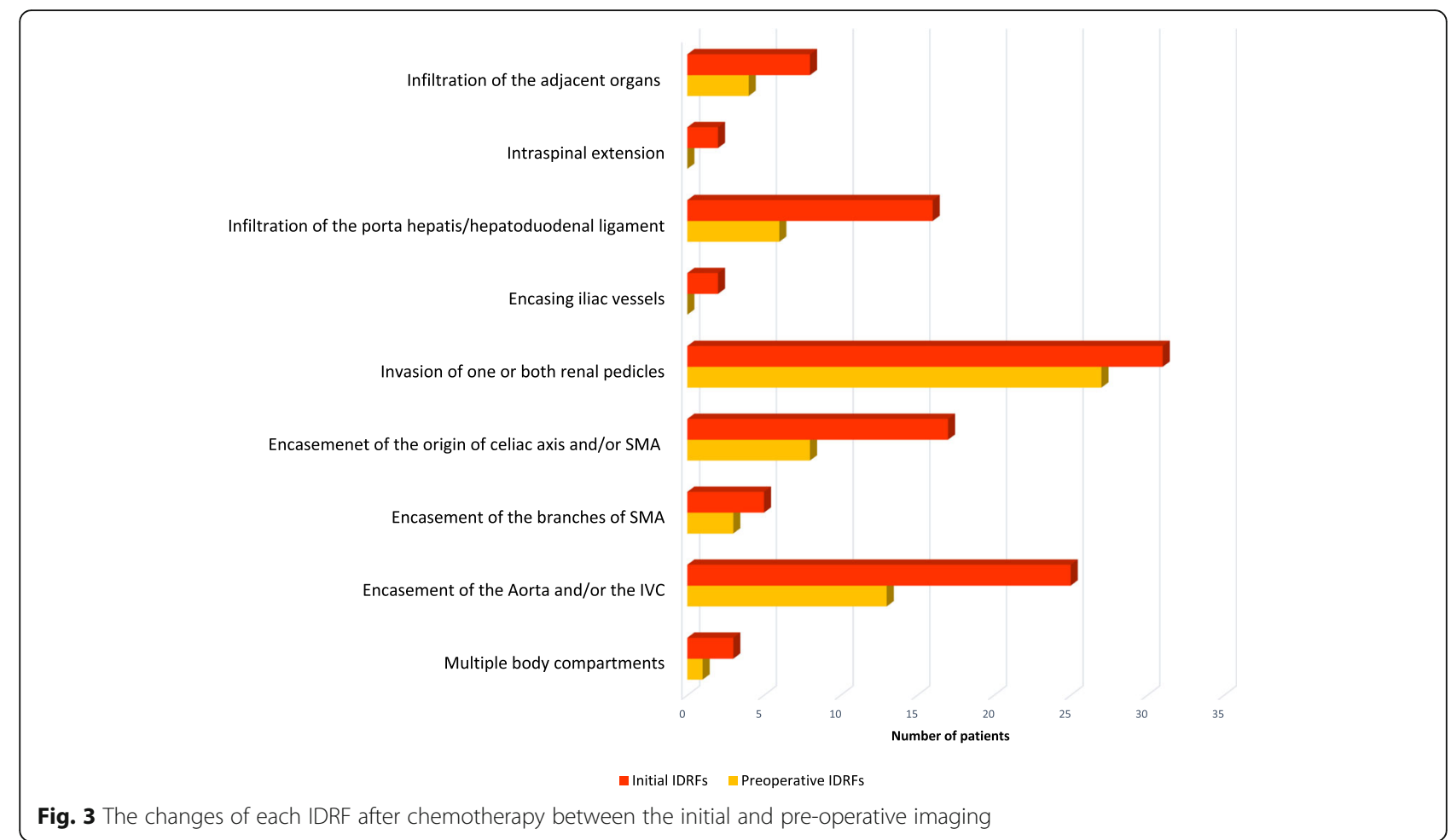

found in 32 cases $(74.4 \%)$ followed by encasement of the aorta and/or IVC in 17 cases (39.5\%) (Fig. 2).

Regarding chemotherapy changes, 39 cases received chemotherapy, of which the changes of the IDRFs after chemotherapy were studied in 35 cases with available initial and pre-operative imaging. Twelve cases have shown stable image-defined risk factors with no changes, 17 cases have shown decrease of the number of IDRFs, and 6 cases have shown total disappearance of the IDRFs (i.e., 12 cases $(34.3 \%)$ have shown stable status of the IDRFs with 23 cases (65.7\%) showing disappearance of at least one IDRF).
Changes of each IDRF after chemotherapy between the initial and pre-operative imaging are demonstrated in Fig. 3, with the least sensitive IDRF to chemotherapy changes that was the invasion of the renal pedicles. No significant correlation was found between the change of IDRFs after chemotherapy with the surgical resectability and complications.

Regarding the surgical data, primary surgery was performed in 4 cases $(9.3 \%)$, while secondary surgery (preceded by chemotherapy) was performed in 39 cases (90.7\%). For the surgical resectability, complete resection was achieved in 15 cases (34.9\%) (Fig. 4), near complete/
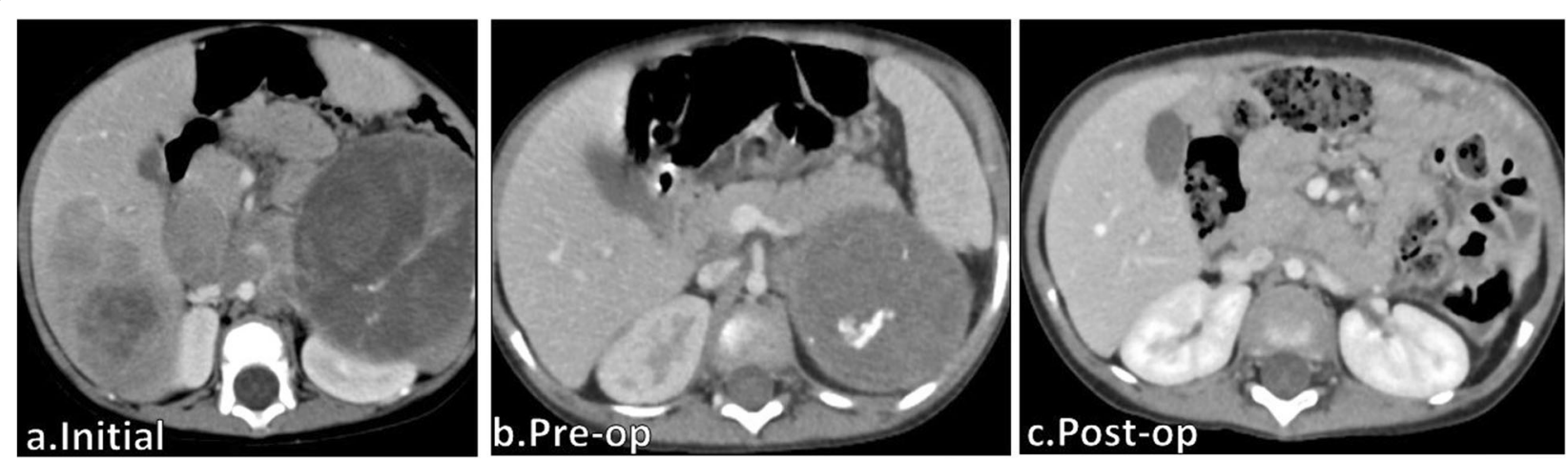

Fig. 4 A 45-week-old male. a Initial CT axial cut revealed left suprarenal mass lesion with enlarged abdominal lymph nodes encasing the aorta, as well as liver metastasis. b Pre-operative $C T$ axial cut showing regressive course regarding the size of the left suprarenal mass and abdominal lymph node with disappearance of all IDRFs. c Post-operative CT axial cuts revealed clear operative bed with no evidence of residual mass lesions 

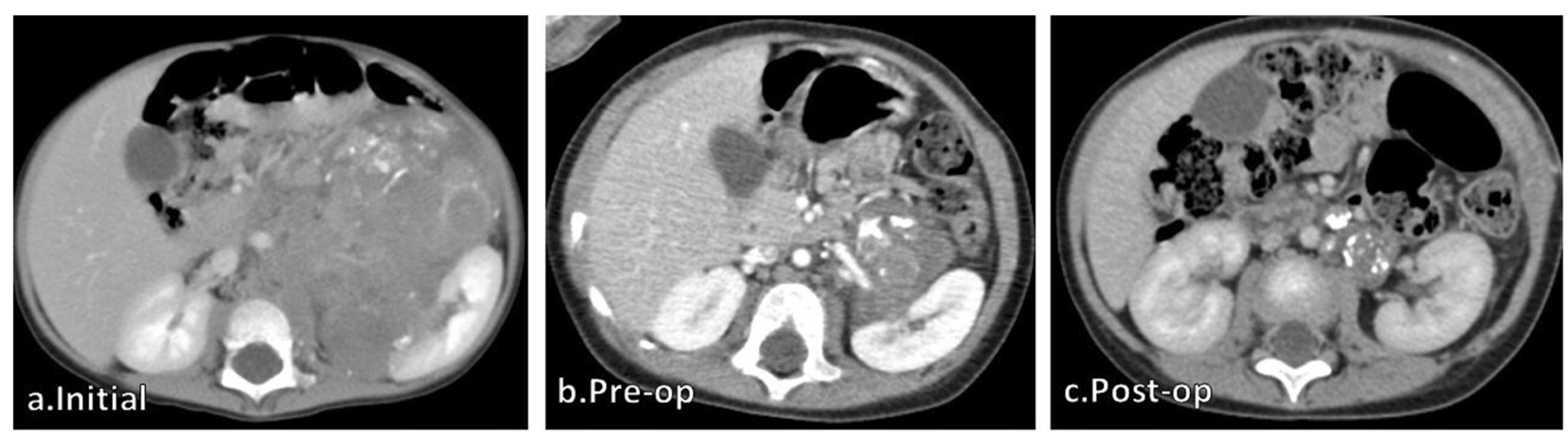

Fig. 5 A 2.5-year-old female. a Initial CT axial cut showing infiltrative neuroblastoma, encasing the aorta, invading the left renal pedicle, and infiltrating the left kidney. b Pre-operative CT axial cut showing regressive course of the mass lesion, still invading the left renal pedicle, and infiltrating the left kidney. c Post-operative CT axial cut showing operative bed residual lesion $>10 \%$ of the tumor volume

subtotal resection in 13 cases (30.2\%) (Fig. 5), incomplete resection $(50-89 \%)$ in 8 cases $(18.6 \%)$, and biopsy/ $<50 \%$ resection in 7 cases (16.3\%) (Fig 6).

There was statistically significant correlation between the pre-operative IDRFs and surgical resectability, where complete resection was achieved in 7 cases with preoperative IDRFs, and 8 cases with no pre-operative IDRFs. Biopsy $/>50 \%$ resection was achieved in 7 cases with pre-operative IDRFs, with $P$ value equals 0.009 (Table 4) (Fig. 7).

Regarding each IDRF, statistically significant correlation was found between surgical resectability and the following IDRFs (multiple body compartments, encasement of the aorta/IVC, encasement of the origin of celiac axis and/or SMA artery, encasement of the branches of SMA at the mesenteric root, invasion of one or both renal pedicles, infiltration of the porta-hepatis, or hepatoduodenal ligament).

The involvement of multiple body compartments was present in two cases and both were associated with resection $<50 \%$, with significant $P$ value of 0.023 .

Encasement of the aorta and/or the IVC was present in 17 cases; in which in 10 cases, the resection was incomplete $(50-89 \%)$ or biopsy/> $50 \%$ resection, with significant $P$ value of 0.021 .

Encasement of the branches of the superior mesenteric artery at the mesenteric root was present in 3 cases, and incomplete resection (50-89\%) was achieved in 1 case and biopsy/> 50\% resection in 2 cases, with significant $P$ value of 0.021 .

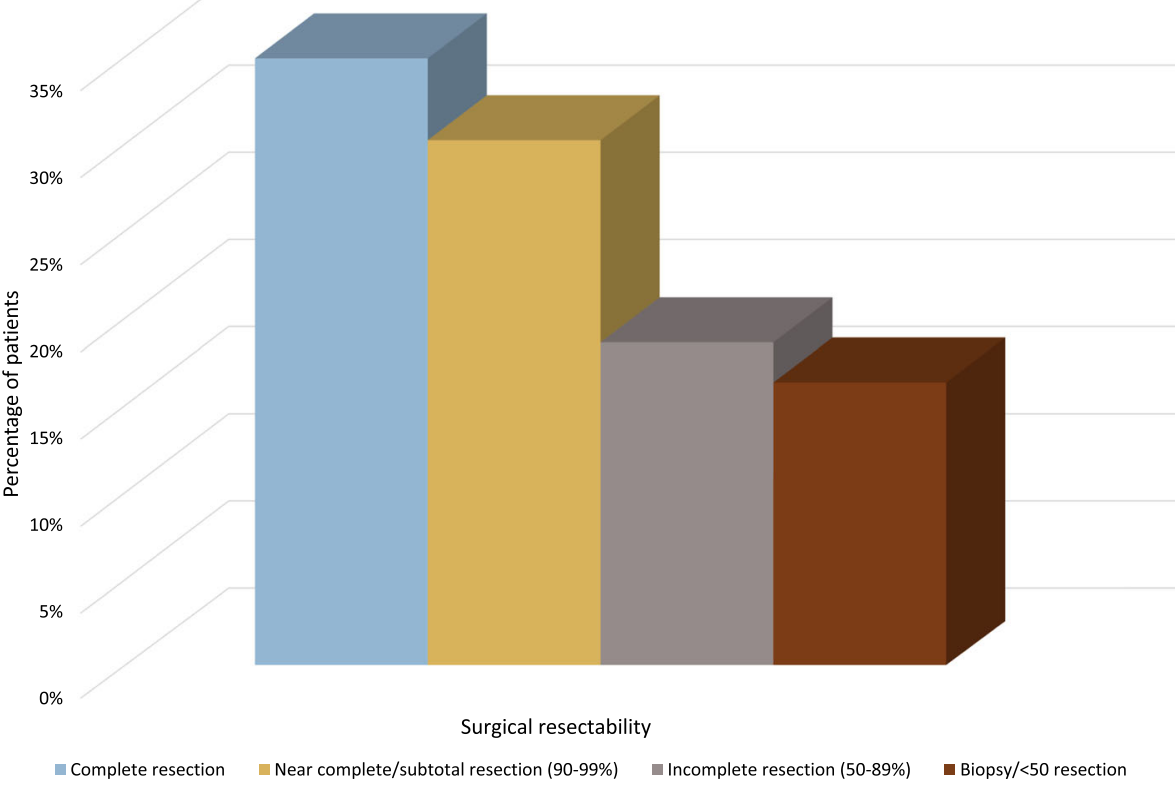

Fig. 6 The percentages of the different extents of surgical resections 
Table 4 Correlation between the pre-operative IDRFs and surgical resectability

\begin{tabular}{|c|c|c|c|c|c|c|}
\hline & & \multicolumn{4}{|c|}{ Pre-operative IDRFs } & \multirow[t]{3}{*}{$P$ value } \\
\hline & & \multicolumn{2}{|l|}{ Present } & \multicolumn{2}{|l|}{ Absent } & \\
\hline & & Count & $\%$ & Count & $\%$ & \\
\hline \multirow[t]{4}{*}{ Surgical resectability } & Complete 100\% & 7 & $21.2 \%$ & 8 & $80.0 \%$ & 0.009 \\
\hline & Near Complete/Subtotal 90-99\% & 12 & $36.4 \%$ & 1 & $10.0 \%$ & \\
\hline & Incomplete 50-89\% & 7 & $21.2 \%$ & 1 & $10.0 \%$ & \\
\hline & Biopsy $/<50 \%$ resection & 7 & $21.2 \%$ & 0 & $0.0 \%$ & \\
\hline
\end{tabular}

Encasement of the origin of the celiac axis and/or superior mesenteric artery was present in 9 cases. Complete resection was achieved in just one case, and near complete/subtotal resection was achieved in one case, incomplete resection (50-89\%) in 2 cases, and biopsy/ $>50 \%$ resection in 5 cases, with significant $P$ value of 0.004 .

Invasion of one or both renal pedicles was present in 32 cases. Complete resection was achieved in 7 cases, and near complete/subtotal resection was achieved in 12 cases, incomplete resection (50-89\%) in 7 cases, and biopsy $/>50 \%$ resection in 6 cases, with significant $P$ value of 0.030 .

Infiltration of the portahepatis or hepatoduodenal ligament was present in 7 cases, and complete resection was achieved in only one case, incomplete resection (50$89 \%)$ in 2 cases, and biopsy/> 50\% resection in 4 cases, with significant $P$ value of 0.004 .

Both intraspinal extension and infiltration of the adjacent structures show no significant correlation with the surgical resectability.

Surgical complications were detected in 13 cases (30.2\%) and absent in 30 cases (69.8\%).
The surgical complications detected include nephrectomy (4 cases) (Fig. 8), renal tear in 1 case, and was primary repaired, and diaphragmatic tear in 3 cases, resulting in pleural effusion and lung collapse in 2 cases. Also, the surgical complications include vascular injuries as follows: IVC ( 2 cases) immediately repaired, one of the hepatic veins (1 case) immediately repaired, renal vessels (4 cases) with associated renal infractions, and one case show post-operative mild renal atrophy (Fig. 9), as well as the superior mesenteric artery (1 case), resulting in caecum and ileal loops ischemia. Exploration was done, and interposition of saphenous graft, yet extensive mesenteric ischemia, resulted in death (considered surgical death), in the same case splenic infarctions were also noted (Fig. 10).

Out of the 13 cases with surgical complications, preoperative IDRFs were present in 12 cases. Yet, no statistical significant correlation was noted between the presence or absence of the pre-operative IDRFs and the surgical complications (Table 5) (Fig. 11).

In correlation of each IDRF and the surgical complications, only the infiltration of the porta-hepatis or hepatoduodenal ligament was found to be statistically significant,

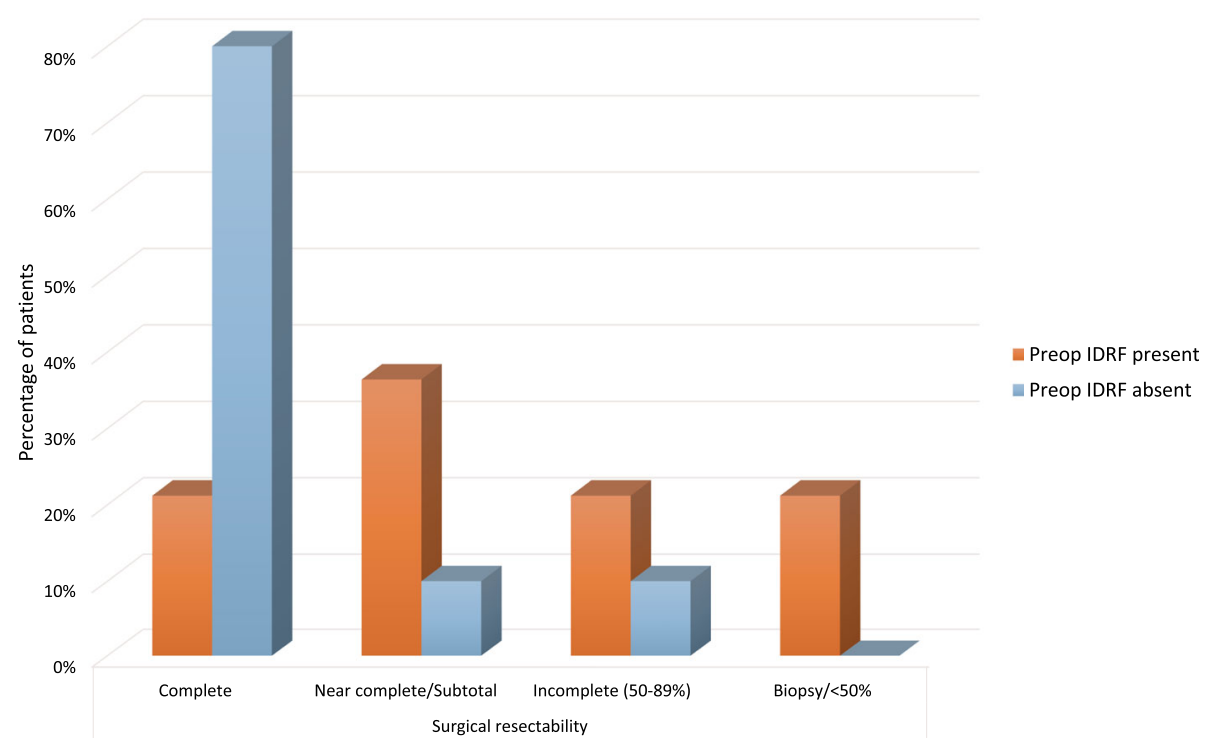

Fig. 7 Correlation between the pre-operative IDRFs and the surgical resectability 

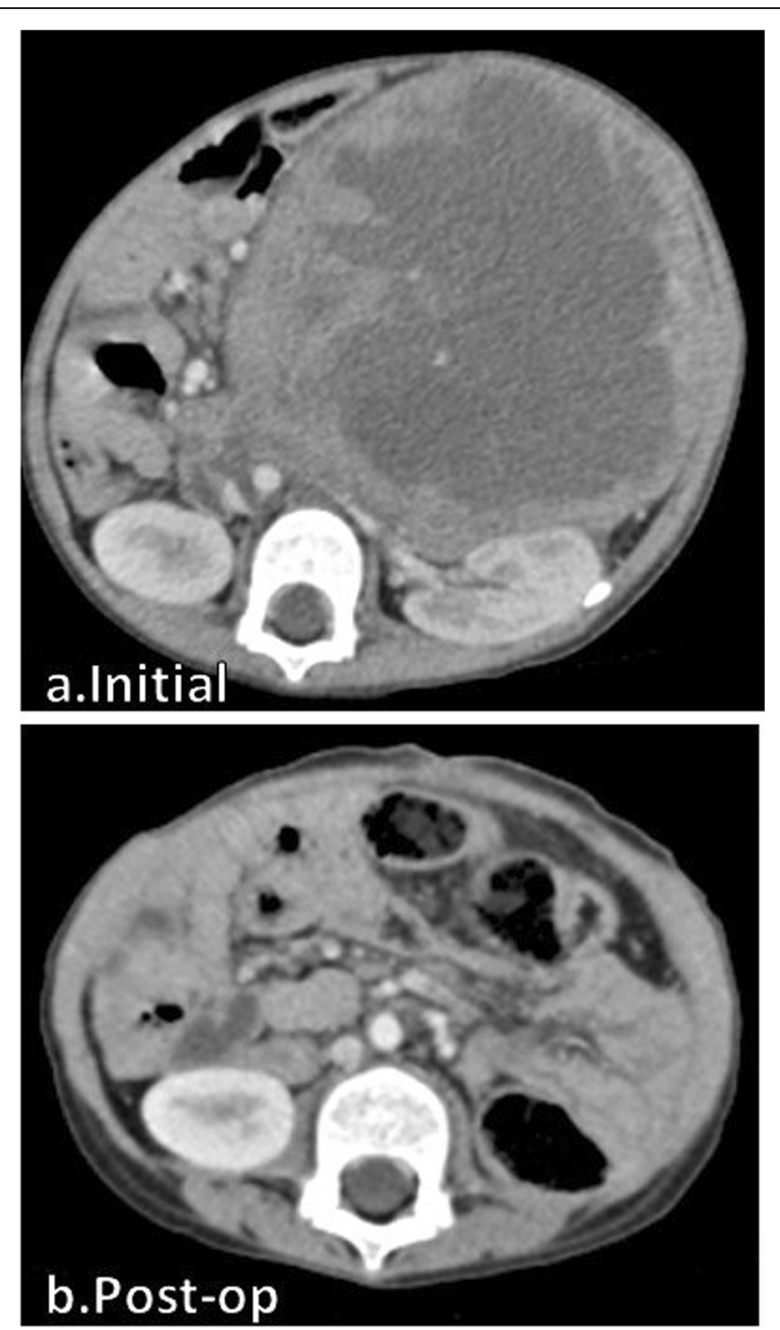

Fig. 8 A 3-year-old female. a Initial CT axial cut showing huge abdominal neuroblastoma, flattening (encasing) the left renal vein, displacing (not infiltrating) the left kidney, posteriorly. b Postoperative CT axial cut showing evidence of left nephrectomy with clear operative bed

where it was present in 7 cases, 5 of which show complications, with significant $P$ value of 0.019 .

No statistical significant correlation was found between the MYCN gene amplification or the histological classification with the presence of initial IDRFs, the change of IDRFs after chemotherapy, surgical resectability, or the surgical complications.

\section{Discussion}

Several studies were developed to assess the validity of the use of the IDRFs in staging neuroblastoma and to assess its relation with the surgical resectability and complications. The aim of our study was to find the relation between pre-operative IDRFs and both the surgical outcomes and complications as well as assessing the changes of IDRFs after chemotherapy.

In our study, pre-operative IDRFs were present in 33 cases $(76.7 \%)$, with the most two frequent IDRFs were invasion of the renal pedicles followed by encasement of the aorta or IVC. This is consistent with Cehchetto et al. [10] and Gunther et al. [11] in both studies of invasion of the renal pedicles followed by encasement of the aorta and IVC were the most frequent IDRFs.

Regarding surgical resectability, we found a significant correlation between the presence of pre-operative IDRFs and the surgical resectability where complete resection was achieved in 7 cases (21.2\%) with pre-operative IDRFs and 8 cases $(80.0 \%)$ with no pre-operative IDRFs $(P$ value $=0.009)$. These results were consistent with the LNESG1 study of the European International Society of Pediatric Oncology Neuroblastoma Group (SIOPEN) [10] which showed that complete excision was achieved in 271 of $363(74.6 \%)$ patients without IDRFs and in 72 of $155(46.4 \%)$ patients with IDRFs $(P$ value $=0.0001)$.

Our results are also consistent with the German Society for Pediatric Haematology and Oncology (GPOH) NB97 trial [12], which involved 366 patients, where complete primary resection was achieved in 156/227 (68.7\%) patients without IDRF and 43/139 (30.9\%) patients with IDRF $(P<0.001)$.

These results denote that complete tumor resection was more likely if IDRF was not present, and one might expect lower primary complete resection rates if the surgical approach is guided by IDRF.

In our study, the complete resection rate if no IDRF was found was $80 \%$, which also was very similar between LNESG1 (74.6\%) and the NB97 trial (68.7\%). However, the presence of IDRF does not necessarily indicate unresectability (complete resection was possible despite IDRF in our study in 7 cases (21.2\%), 46\% in the LNESG1 study, and $30.9 \%$ in the NB97 trial).

IDRFs are not to be taken as an absolute contraindication to surgery, as developments in surgical techniques facilitate handling some of the aforementioned IDRFs. What we recommend is surgical planning according to the IDRFs present.

Other studies that support these results include Irtan et al. who involved 39 operated patients and found that the quality of resection correlated with the pre-operative IDRFs $(P<0.001)$ [13]. A study by Pohl et al. conducted on 102 patients revealed that tumors of IDRF-negative patients had complete or near-complete resection of the primary tumors, with significant correlation ( $P$ value 0.001$)$ [14]. Another study by Penazzi et al. 2017 which has retrospectively involved 27 patients also supports these results showing significant correlation between the resectability and pre-operative IDRFs ( $P$ value 0.0019) [15].

Regarding the surgical complications, our study surgical complications were present in 13 cases, in which 

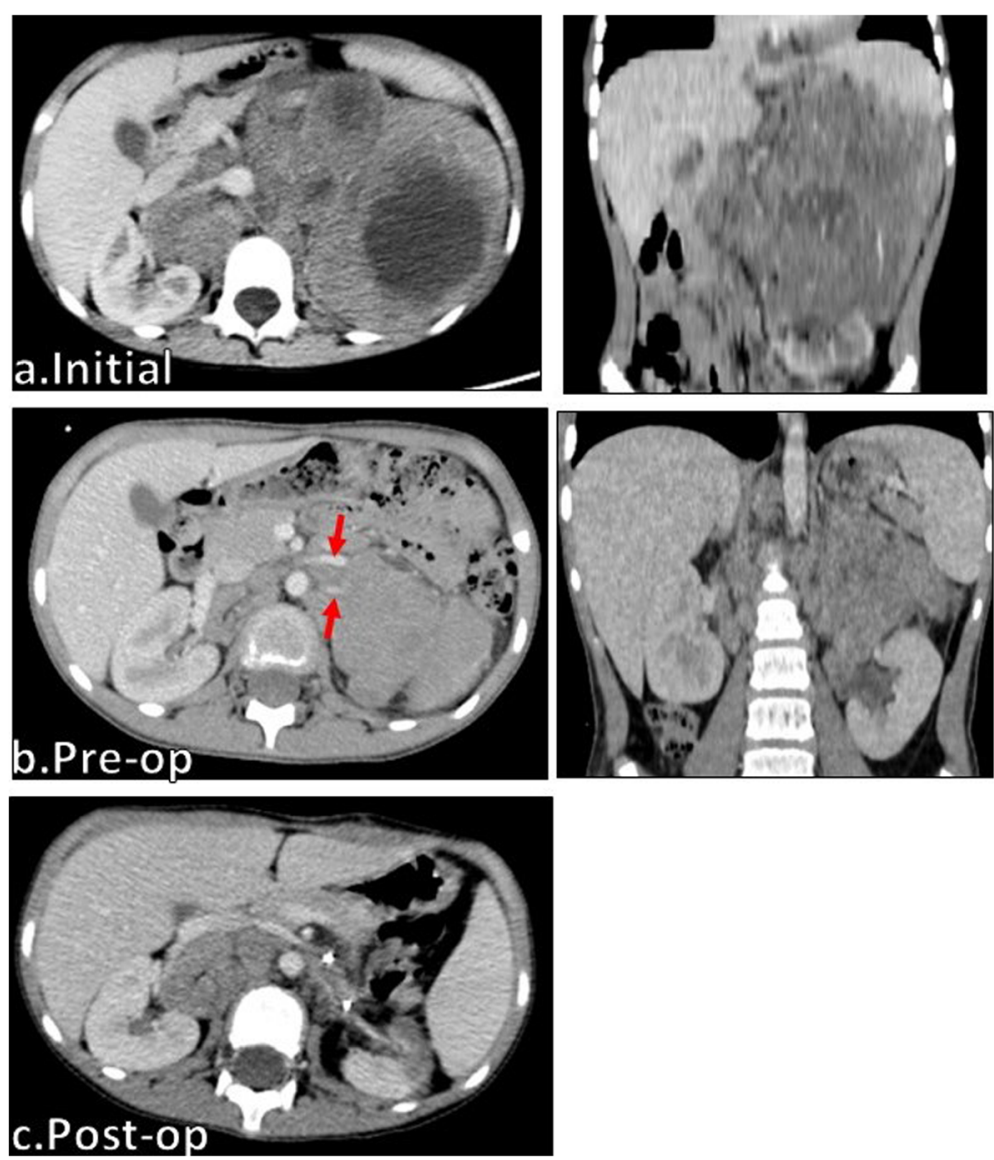

Fig. 9 A 7-year and 9-month-old female. a Initial CT axial and coronal cuts showing abdominal neuroblastoma lesion encasing the aorta, SMA, renal pedicles, and infiltrating the left kidney. $\mathbf{b}$ Pre-operative $\mathrm{CT}$ axial and coronal cuts show regressive course regarding the size of the lesion with disappearance of most of the IDRFs except for the encasement of the left renal vessels (red arrows). c Post-operative CT axial cut showing small sized left kidney with renal infarcts, with progression of the residual retrocaval component

pre-operative IDRFs were present in 12 cases. Yet, no statistical significant correlation was noted between the presence or absence of the pre-operative IDRFs and the surgical complications.

In the GPOH NB97 trial [12], significant correlation was found between the presence of any IDRF and complications, where 70 patients out of the 366 patients of the study show complications in which IDRFs were present in 37 patients with significant $P$ value of 0.006 .

This was consistent with Gunther et al. [11], where complications were present in 7 patients out of the 60 patients involved in the study, and in all of these cases, at least one IDRF was present.

Pohl et al.'s 2016 study [14] showed that surgical complications occurred in 21 patients, 19 of them showed one or more IDRF, and 2 patients were IDRF-negative. However, the statistical analysis for IDRF-status and complications was not significant.

Also, in Avanzini et al.'s 2017 SIOPEN study [16] involving 143 patients, out of 14 case with complications,
IDRFs were just found in 3 cases, with also no significant correlation.

Regarding the chemotherapy effect and changes of IDRFs, from 35 cases studied for the changes of IDRFs after chemotherapy, 12 cases (34.3\%) show stable status of the IDRFs, with 23 cases (65.7\%) show disappearance of at least one IDRF, with the invasion of the renal pedicles that was the least sensitive IDRF to be affected by chemotherapy. No significant correlation was found between the change of IDRFs after chemotherapy and the surgical resectability with $P$ value of 0.58 .

This is consistent with Irtan et al.'s 2015 study [13], where from the 39 patients who received chemotherapy, 21 patients $(53.8 \%)$ lost at least one IDRF, while the remaining 18 patients $(46.2 \%)$ had no change in the number of IDRFs, with the IDRFs that seemed least sensitive to chemotherapy that was the invasion of the renal pedicle. Also, there is no significant correlation between the decline in the number of IDRFs after chemotherapy and the surgical resectability, with $P$ value of 0.87 . 


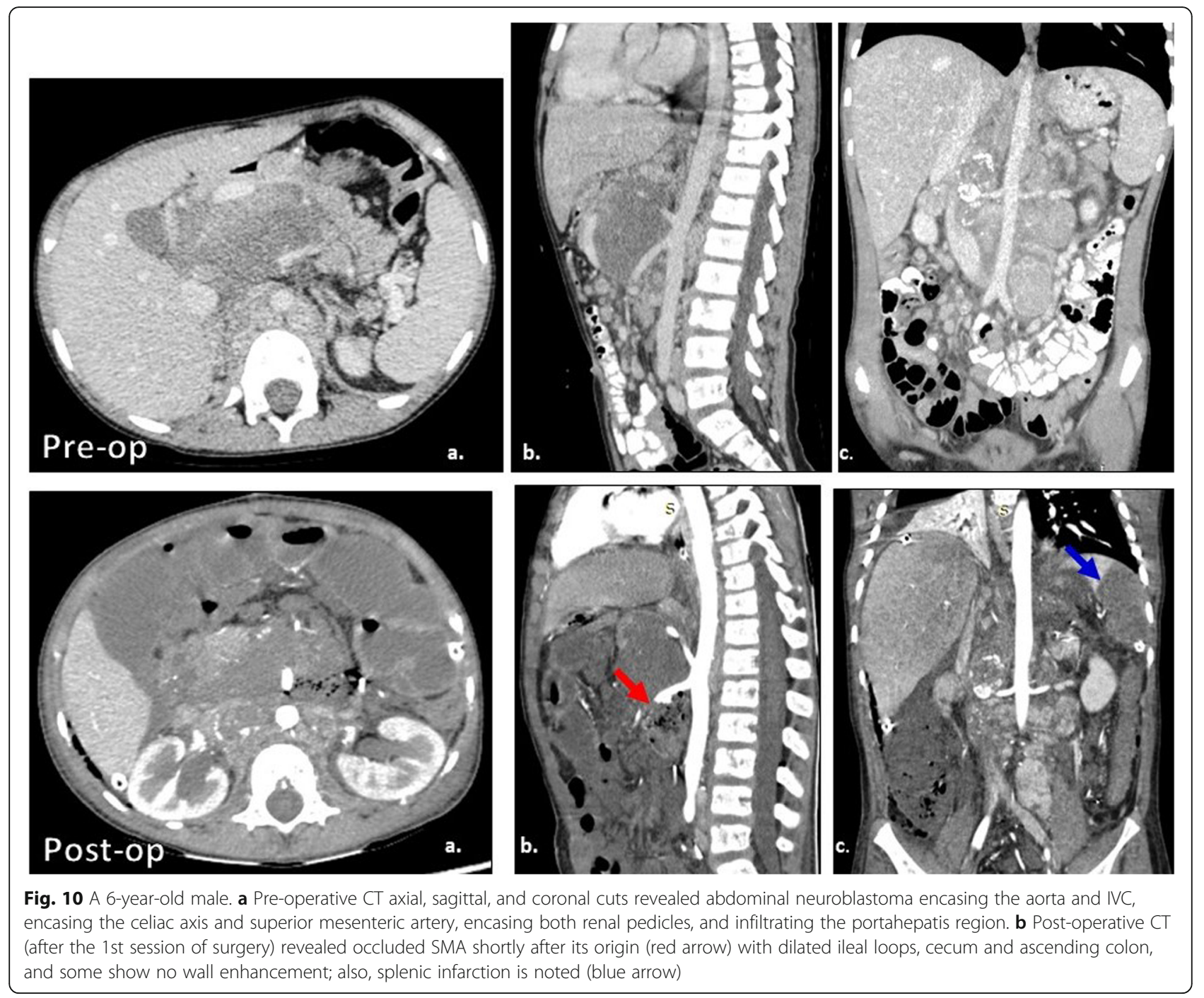

According to Avanzini et al.'s 2017 study [16], in the studied 143 patients, complete disappearance of IDRF was observed in 33 patients (23.1\%), reduction of IDRF without complete disappearance was found in 13 patients $(9.1 \%)$, and no change in IDRF number or type was found in 70 patients (49\%). Disappearance of some IDRF but the appearance of others occurred in 15 patients $(10.5 \%)$. Twelve patients $(8.3 \%)$ had tumors that acquired new IDRF during chemotherapy without any modification of those described at diagnosis.

\section{Conclusion}

This study provides evidence that the IDRFs of neuroblastoma are useful indicators for predicting surgical resectability and the risk of surgical complications, and

Table 5 Correlation between the pre-operative IDRFs and the surgical complications

\begin{tabular}{|c|c|c|c|c|c|c|}
\hline & & \multicolumn{4}{|c|}{ Pre-operative IDRFs } & \multirow[t]{3}{*}{$P$ value } \\
\hline & & \multicolumn{2}{|l|}{ Yes } & \multicolumn{2}{|l|}{ No } & \\
\hline & & Count & $\%$ & Count & $\%$ & \\
\hline \multirow[t]{2}{*}{ Presence of complications } & Present & 12 & $36.4 \%$ & 1 & $10.0 \%$ & 0.237 \\
\hline & Absent & 21 & $63.6 \%$ & 9 & $90.0 \%$ & \\
\hline
\end{tabular}




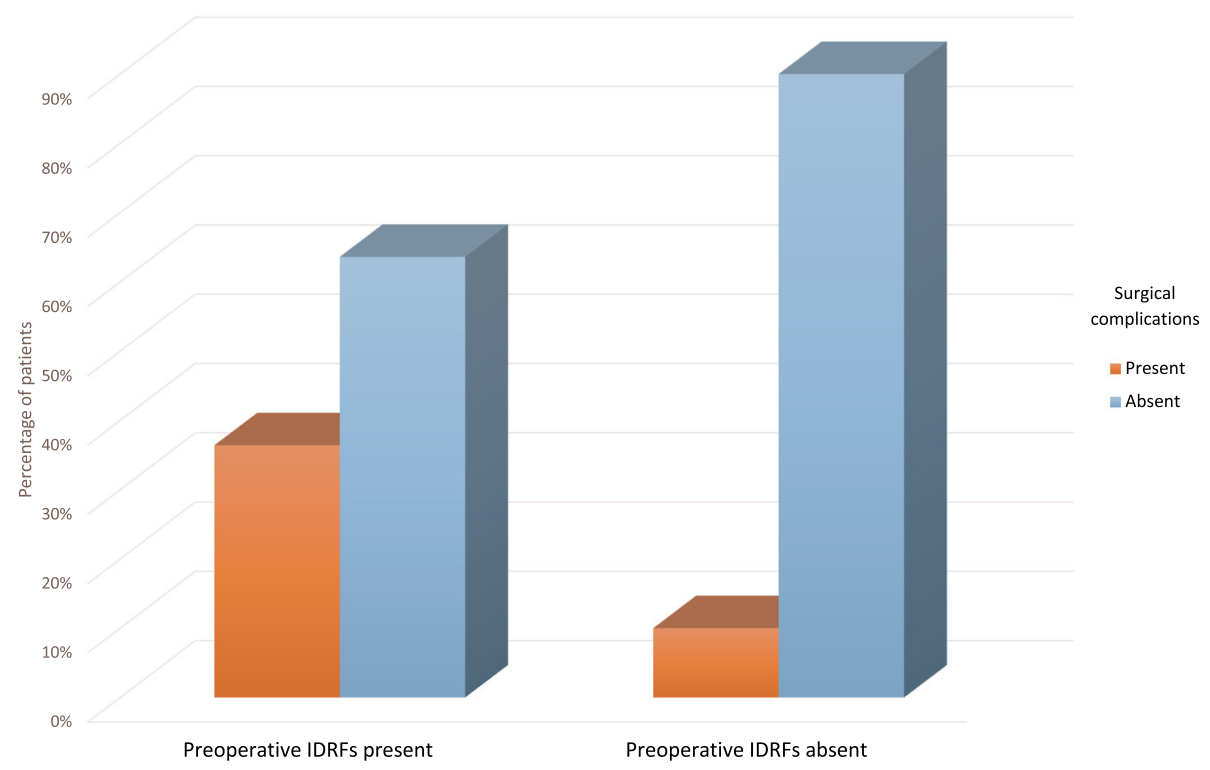

Fig. 11 Correlation between the pre-operative IDRFs and the surgical complications

should be taken into consideration in surgical planning to improve the outcome.

The main limitation of the study was the large number of high risk patients compared to fewer cases of low and intermediate risk patients in our hospital, for which we recommend larger studies to be conducted in different hospitals to achieve the variety of cases.

\section{Abbreviations}

DNA: Deoxyribonucleic acid; NB: Neuroblastoma; CT: Computed tomography; MRI: Magnetic resonance imaging; INSS: The International neuroblastoma staging system; INRGSS: The International Neuroblastoma Risk Group staging system; INRG: The International Neuroblastoma Risk Group; IDRFs: Imagedefined risk factors; SRFs: Surgical risk factors; COG: Children's oncology group

\section{Authors' contributions}

The authors read and approved the final manuscript.

\section{Competing interests}

The authors declare that they have no competing interests.

\section{Author details}

'National Cancer Institute, Cairo university, Kasr El- Aini St., Fom El Khalig, Cairo, Egypt. ${ }^{2}$ Faculty of Medicine, Cairo University, Giza, Egypt. ${ }^{3}$ Department of surgery, Faculty of Medicine, Helwan University, Helwan, Egypt.

Received: 27 March 2020 Accepted: 13 May 2020

Published online: 02 June 2020

\section{References}

1. Swift CC, Eklund MJ, Kraveka JM, Alazraki AL. (2018). Updates in diagnosis, management, and treatment of neuroblastoma. Radiographics, 38(2):566580. https://doi.org/10.1148/rg.2018170132.

2. Ward E, DeSantis C, Robbins A, Kohler B, Jemal A. (2014). Childhood and adolescent cancer statistics. CA Cancer J Clin 64(2):83-103. https://doi.org/10. 3322/caac.21219.

3. Mullassery, D., \& Losty, P. D. (2015). Neuroblastoma. Paediatr Child Health, Volume 26, Issue 2, 68 - 72. https://doi.org/10.1016/j.paed.2015.11.005.
4. Dumba M, Jawad N, McHugh K. (2015). Neuroblastoma and nephroblastoma: a radiological review. Cancer Imaging, 15(1):5. https://doi. org/10.1186/s40644-015-0040-6.

5. Kembhavi SA, Shah S, Rangarajan V, Qureshi S, Popat P, Kurkure P. (2015). Imaging in neuroblastoma: an update. The Indian journal of radiology \& imaging, 25(2):129. https://doi.org/10.4103/0971-3026.155844.

6. Brisse HJ, McCarville MB, Granata C, Krug KB, Wootton-Gorges SL, Kanegawa K, Giammarile F, Schmidt M, Shulkin BL, Matthay KK, Lewington VJ. (2011). Guidelines for imaging and staging of neuroblastic tumors: consensus report from the international neuroblastoma risk group project. Radiology, 261(1):243-257. https://doi.org/10.1148/radiol.11101352.

7. Brodeur GM, Pritchard J, Berthold F, Carlsen NL, Castel V, Castelberry RP, De Bernardi B, Evans AE, Favrot M, Hedborg F. (1993). Revisions of the international criteria for neuroblastoma diagnosis, staging, and response to treatment. J Clin Oncol, 11(8):1466-1477. https://doi.org/10.1200/JCO.1993. 11.8.1466.

8. Monclair T, Brodeur GM, Ambros PF, Brisse HJ, Cecchetto G, Holmes K, Kaneko M, London WB, Matthay KK, Nuchtern JG, von Schweinitz D. (2009). The international neuroblastoma risk group (INRG) staging system: an INRG task force report. J Clin Oncol, 27(2):298. https://doi.org/10.1200/JCO.2008. 16.6876

9. Chan YH (2003) Biostatistics 103: qualitative data-tests of independence. Singap Med J 44(10):498-503

10. Cecchetto G, Mosseri V, De Bernardi B, Helardot P, Monclair T, Costa E, Horcher E, Neuenschwander S, Tomà P, Rizzo A, Michon J. (2005). Surgical risk factors in primary surgery for localized neuroblastoma: the LNESG1 study of the European International Society of Pediatric Oncology neuroblastoma Group. J Clin Oncol, 23(33):8483-8489. https://doi.org/10. 1200/JCO.2005.02.4661.

11. Günther P, Holland-Cunz S, Schupp CJ, Stockklausner C, Hinz U, Schenk JP. (2011). Significance of image-defined risk factors for surgical complications in patients with abdominal neuroblastoma. Eur J Pediatr Surg, $21(05)$ :314317. https://doi.org/10.1055/s-0031-1280824

12. Simon T, Hero B, Benz-Bohm G, von Schweinitz D, Berthold F. (2008). Review of image defined risk factors in localized neuroblastoma patients: results of the GPOH NB97 trial. Pediatr Blood Cancer, 50(5):965-969. https:// doi.org/10.1002/pbc.21343.

13. Irtan, S., Brisse, H.J., Minard-Colin, V., Schleiermacher, G., Galmiche-Rolland, L., Le Cossec, C., Elie, C., Canale, S., Michon, J., Valteau-Couanet, D. and Sarnacki, S. (2015). Image-defined risk factor assessment of neurogenic tumors after neoadjuvant chemotherapy is useful for predicting intraoperative risk 
factors and the completeness of resection. Pediatr Blood Cancer, 62(9), pp 1543-1549. https://doi.org/10.1002/pbc.25511.

14. Pohl A, Erichsen M, Stehr M, Hubertus J, Bergmann F, Kammer B, von Schweinitz D. (2016). Image-defined risk factors correlate with surgical radicality and local recurrence in patients with neuroblastoma. Klin Padiatr, 228(03):1 18-123. https://doi.org/10.1055/s-0041-111175

15. Penazzi AC, Tostes VS, Duarte AA, Lederman HM, Caran EM, Abib SD. (2017). Do the radiological criteria with the use of risk factors impact the forecasting of abdominal neuroblastic tumor resection in children?. ABCD. Arquivos Brasileiros de Cirurgia Digestiva (São Paulo), 30(2):88-92. https://doi. org/10.1590/0102-6720201700020003.

16. Avanzini S, Pio L, Erminio G, Granata C, Holmes K, Gambart M, Buffa P, Castel V, Valteau Couanet D, Garaventa A, Pistorio A. (2017). Image-defined risk factors in unresectable neuroblastoma: SIOPEN study on incidence, chemotherapy-induced variation, and impact on surgical outcomes. Pediatric blood \& cancer., 64(11):e26605. https://doi.org/10.1002/pbc.26605.

\section{Publisher's Note}

Springer Nature remains neutral with regard to jurisdictional claims in published maps and institutional affiliations.

\section{Submit your manuscript to a SpringerOpen ${ }^{\mathcal{O}}$ journal and benefit from:}

- Convenient online submission

- Rigorous peer review

- Open access: articles freely available online

- High visibility within the field

- Retaining the copyright to your article

Submit your next manuscript at $\boldsymbol{\nabla}$ springeropen.com 